CP, 2014 , N4, pp. 77-86. ISSN 2014-6752. Girona (Catalunya). CHÁVEZ ORDÓÑEZ, Verónica Itzel: ¿Qué pasa cuando los receptores crean? Expansión narrativa de una serie animada por medio de las creaciones de los fans.

Recibido: 22/05/2014 - Aceptado: 29/07/2014

\title{
¿QUÉ PASA CUANDO LOS RECEPTORES CREAN? EXPANSIÓN NARRATIVA DE UNA SERIE ANIMADA POR MEDIO DE LAS CREACIONES DE LOS FANS.
}

\author{
What happen when the audience create? Narrative expansiono o fan animated serie \\ through fanarts.
}

\author{
Autores: CHÁVEZ ORDÓÑEZ, Verónica Itzel \\ Investigadora Maestranda - Universidad de Guadalajara-México-itzchavezz@ gmail.com
}

\section{Resumen}

Las transformaciones que Internet ha traído para los medios de comunicación, tanto en la producción de contenidos como en los procesos de recepción son inauditas. Estas transformaciones en los contenidos televisivos han traído simultáneamente, y casi en un sentido de reciprocidad una modificación en las dinámicas de recepción. Se empieza a recurrir con mayor frecuencia al nombre de "prosumidores" (Scolari, 2009; 2012), es decir, consumidores que han dejado el lado pasivo de audiencia para convertirse en sujetos activos que además de consumir, producen. Los receptores de la era digital cuentan con mayores herramientas para apropiarse, cuestionar, discutir o negociar los mensajes expuestos por los medios. En el presente trabajo, pretendo indagar en los contenidos creados por los fanáticos de una serie de ficción de dibujos animados llamada Hora de Aventura (Adventure Time). Mi intención es observar de qué manera se despliega, modifica o cuestiona la narrativa implicada por la televisión con el relato canon del dibujo animado, por medio de los fanarts producidos por los receptores activos. La metodología utilizada fue aquella dictada desde la narratología por el grupo de investigación de Carlos Scolari (2012) para analizar las narrativas transmedia, centrándome en las dimensiones para los contenidos creados por los usuarios y la expansión narrativa, así como las discrepancias entre los contenidos creados por productores y receptores, mencionadas por Henry Jenkins (2009) para hablar de las narrativas transmedia. Los resultados de esta investigación confirman que los receptores modifican el relato canon a través de estrategias narrativas como la intertextualidad, la reinvención, el cambio del género sexual de los personajes, la creación de nuevas parejas, la proyección del futuro de los personajes, etc. Los prosumidores se apoderan del mundo diegético propuesto por la televisión, y lo adaptan a su voluntad. Por otro lado también se encontró que en algunas ocasiones los fanarts se utilizan no para modificar sino para hacer énfasis en el relato canon, a través del humor y la reflexión.

\section{Palabras clave}

narrativa, transmedia, fanarts, prosumidores, animación

\begin{abstract}
The changes that the Internet has brought to the media, both in content production and reception processes are unprecedented. These transformations have brought television content simultaneously, and almost a sense of reciprocity in a change in the dynamics of reception. It starts to make greater use of the name "prosumers " ( Scolari , 2009 , 2012), consumers who have left the passive side of audience to become active subjects in addition to eating produce. Recipients of the digital age have greater tools to appropriate, question, discuss or negotiate the messages presented by the media. In this paper, I intend to delve into the content created by fans of a cartoon called Adventure Time. My intention is to observe how the narrative unfolds the story canon, amended or questioned, through the fanarts produced by active receptors. I will use the analysis model proposed by the research group of Carlos Scolari (2012), to discuss transmedia narratives, based on narrative theory and semiotic theory, focusing on the dimension that addresses the content created by users, and some concepts for discrepancies between the content created by producers and receivers, mentioned by Henry Jenkins (2009) to discuss the transmedia narrative.
\end{abstract}

\section{Key words}

Transmedia storytelling, user-generated content, fiction, crossmedia, prosumers, animation 


\section{Introducción}

Las transformaciones que Internet ha traído para los medios de comunicación, tanto en la producción de contenidos como en los procesos de recepción son inauditas. Este medio lejos de convertirse en una amenaza para la televisión ha venido a figurar como un catalizador para la gestación de una narrativa distinta, y en muchos sentidos de mayor calidad. Muchos autores como Henry Jenkins (2003), Carlos Scolari (2009), Rincón (2011), Virino (2006), hablan de narrativas que modifican los parámetros establecidos en la televisión, ya sea por su despliegue a través de las distintas plataformas en las que puede expandirse un mundo ficticio (transmedia storytelling); o por los temas, personajes y maneras de contar innovadoras, que dan pauta para un entretenimiento más inteligente.

Estas transformaciones en los contenidos televisivos han traído simultáneamente, y casi en un sentido de reciprocidad una modificación en las dinámicas de recepción. Se empieza a recurrir con mayor frecuencia al nombre de "prosumidores" (Scolari, 2009; 2011), es decir, consumidores que han dejado el lado pasivo de audiencia para convertirse en sujetos activos que además de consumir, producen.

Los receptores de la era digital cuentan con mayores herramientas para apropiarse, cuestionar, discutir o negociar los mensajes expuestos por los medios. En la actualidad es bastante común encontrar páginas web y blogs dedicados exclusivamente a series de ficción o películas, donde se dan una serie de intercambios entre distintos usuarios para interpretar los contenidos expuestos por la televisión, e incluso modificar el relato canon a través de creaciones propias, llamadas fanarts, cuando se trata de ilustraciones o fanfictions, cuando se tejen otras historias (Jenkins, 2003).

Estos nuevos espacios virtuales que Internet ha otorgado para la creación de comunidades de interpretación y re-apropiación nos ha hecho pensar que las audiencias son incluso más activas ahora con la facilidad que existe para exponer nuestros comentarios y tejer redes sociales sin importar la distancia física y geográfica (Orozco, 2007).

Se sugiere que los usuarios de Internet (audiencia) toman las herramientas que tienen a la mano para apropiarse, cuestionar discutir o negociar con otros usuarios, e incluso rebelarse ante los contenidos expuestos por la televisión por medio de los blogs e incluso de sus propias creaciones, que en el caso de las ficciones son llamadas fanart o fanfiction (Jenkins, 2001), y en el de la información y periodismo, periodismo ciudadano o 3.0 (Scolari, 2012).

Nos situamos pues, en cultura hipermediática, donde los desarrollos técnicos están transformando el ecosistema mediático desde la condición de contenidos interactivos, que modifica las relaciones entre productores y consumidores. Las creaciones que realizan los receptores, como los fanfictions o fanarts son uno de los principales productos en los que se puede estudiar esta dinámica. Algunas de las principales discrepancias que encuentra Henry Jenkins (2009) en torno a productores y receptores son la Expansión (Spreadability) contra la Profundidad (Drillability), ambos procesos que amplian la narrativa canon; la Continuidad (Continuity), donde todas las narraciones que se extienden en otras plataformas deben de ser coherentes con la narrativa canon, contra la Multiplicidad (Multiplicity), que admite la producción desde muchos tipos de usuarios y entre tantas propuestas independientes es difícil seguir una coherencia; la Inmersión (Immersion) que tiene que ver con el grado de compenetración del receptor con el contenido de su narrativa favorita, contra la Extraibilidad (Extractability), que consiste en tomar cosas de la ficción para aplicarlas a la vida real. Es en estas estrategias narrativas donde se realiza la pugna entre los contenidos propuestos desde la producción y la recepción, ya que muchas veces las producciones de los prosumidores no van acorde con lo planteado por el relato canon y es algo que no puede regular el productor.

\section{Objetivos}

En el presente trabajo, se pretende indagar en los contenidos creados por los fanáticos de una serie de ficción de dibujos animados llamada Hora de Aventura (Adventure Time). Se selecciona esta serie animada por 
su actualidad y gran éxito en audiencia, además de su notable expansión narrativa en cómics, videojuegos, y fanfictions.

Hora de Aventura (Adventure Time) fue estrenada en 2010 y actualmente es transmitida en Cartoon Network a nivel mundial. Aunque su target inicial son los niños y sigue siendo transmitida como una serie infantil, ha alcanzado una gran popularidad entre adolescentes y adultos. También se ha vuelto viral y convertido en una serie de culto por Internet, por lo que podemos encontrar miles de blogs de fans, páginas de Internet $y$ de Facebook, wikis, fanfictions $y$ fanarts, dedicadas a ella. La intención de esta investigación es observar de qué manera se despliega, modifica o cuestiona la narrativa implicada por la televisión con el relato canon del dibujo animado, por medio de los fanarts producidos por los prosumidores.

\section{Metodología}

En este estudio particular se parte de Internet como cultura, ya que me centro en las negociaciones y dinámicas que ocurren en la red, especialmente en las comunidades de fans de la serie animada Hora de Aventura (Adventure Time).

El recorte que se hizo para el presente estudio se limitó espacialmente a la revisión de una página de Facebook dedicada a este dibujo animado y temporalmente del 15 de abril al 16 de mayo del 2013. El resultado de esta observación fue determinar el corpus de estudio de 127 fanarts. Puesto que se encontró que de 157 publicaciones de la página, 127 eran imágenes de fanart.

Para el análisis del corpus se inició con una clasificación de los tipos de fanart de acuerdo a su contenido y función, considerando algunas de las dimensiones definidas por el grupo de investigación de Carlos Scolari (2012) para analizar los contenidos creados por los usuarios en las narrativas transmedia como: el tipo de contenido, el tipo de relación con los contenidos oficiales, la estrategia de expansión utilizada: espacial, temporal, de personajes o de género y los componentes intertextuales. Con un sustento en la teoría narratológica y semiótica. Por otro lado también se tomarán en cuenta las discrepencias de las que habla Henry Jenkins (2009) entre los contenidos de los productores y los prosumidores: Expansión vs Profundidad; Continuidad vs Multiplicidad; Inmersión vs Extraibilidad.

De los 127 fanarts publicados en la página de Facebook, se establecieron cuatro categorías para clasificar los fanfiction: intertextuales, de reinvención, reflexivos y humorístico, de acuerdo a las dimensiones ya mencionadas para el estudio de las narrativas transmedia. La primera relacionada con la función intertextual; la segunda con la expansión narrativa temporal, espacial y de personajes; la tercera y cuarta con el tipo de contenido. Aquí podemos ver una tabla con la cantidad correspondiente a cada clasificación y los porcentajes respecto al total:

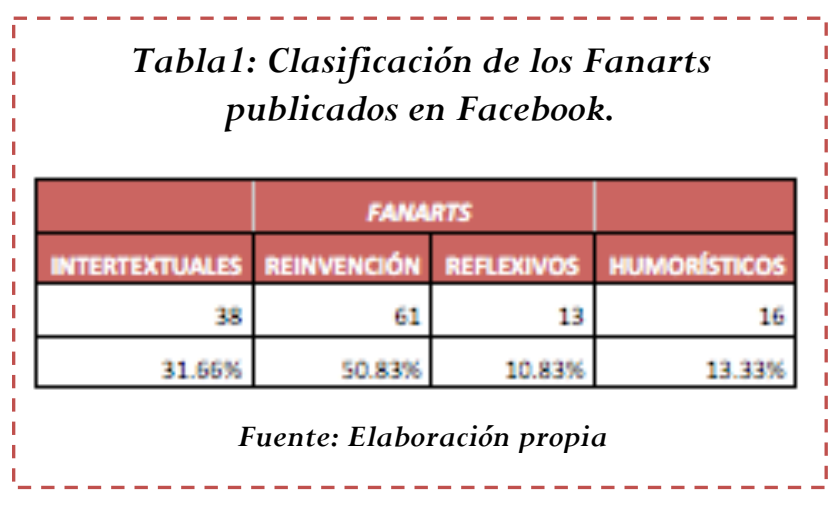

\section{Análisis del fanart}

La página cuenta con más de diez mil seguidores, y tiene actividad muy constante, con un promedio al día de 7 publicaciones (post) por parte del administrador de la página y de 30 a 40 comentarios en torno a las publicaciones. La comunicación que se da entre estos usuarios es generalmente vertical, ya que se trata de una página que es administrada por uno o varios usuarios, y son ellos los que ponen el tema de discusión, generalmente con imágenes tomadas del fanart de esta serie, artículos de 
merchandising (playeras, gorras, videojuegos, peluches) y capítulos que se suben mediante el canal de Youtube. Es interesante señalar que aunque esta comunidad está creada por personas con interés en una serie animada, y el motor principal de los intercambios están centrados en la misma, no es restrictivo hablar de la serie, sino que también se realizan intercambios personales de la vida diaria, generalmente relacionados con la escuela, tareas, y aburrimiento.

Las publicaciones en las que gira la interacción de los participantes de la comunidad virtual, son generalmente de fanarts, es decir, ilustraciones hechas por fans (prosumidores) que muchas veces transgreden la historia oficial de la serie y amplían su mundo diegético. Aquí es interesante analizar las producciones hechas por los prosumidores, para conocer la aportación y apropiación que hacen del mundo narrativo del relato oficial. De acuerdo a los fanarts publicados en este blog podemos clasificarlos en cuatro grupos: 1) Intertextuales, 2) De reinvención, 3) Reflexivos, 4) Humorísticos.

\subsection{Fanarts intertextuales}

El primer grupo de fanarts, corresponde a todas esas ilustraciones que se hacen con los personajes de Hora de Aventura en contextos distintos a su historia, ya sea por el espacio y personajes con los que se encuentran que pueden ser el mundo ficticio de otra caricatura o película o por el vestuario y posturas, que imitan también a personajes de otros mundos ficticios.

Las referencias que se encuentran son generalmente dentro de la cultura popular de los medios de comunicación, muchas veces la alusión es hacia otras animaciones, Pokemon, Dragon Ball, Caballeros del Zodiaco; a videojuegos como Mario Bross, Zelda, Sonic; a películas como Kill Bill, Beetlejuice; y a música, con portadas de discos de distintos grupos, entre ellos Iron Maiden. Es interesante observar que se comparte un universo referencial entre las comunidades de fans de Hora de Aventura, donde generalmente se circula entre las animaciones. A continuación podemos observar uno de los fanarts intertextuales (Gráfico $\mathrm{n}^{\circ} 1$ ), en el que se hace referencia a la película de Kill Bill a través de una parodia del afiche de cine, donde la actriz Uma Turman sale vestida con un traje amarillo completo y una espada, con un fondo amarillo y tipografía negra.
La parodia se hace con Fiona, la variante femenina del personaje principal de Hora de Aventura (Adventure Time), que utiliza el mismo traje amarillo y fondo.

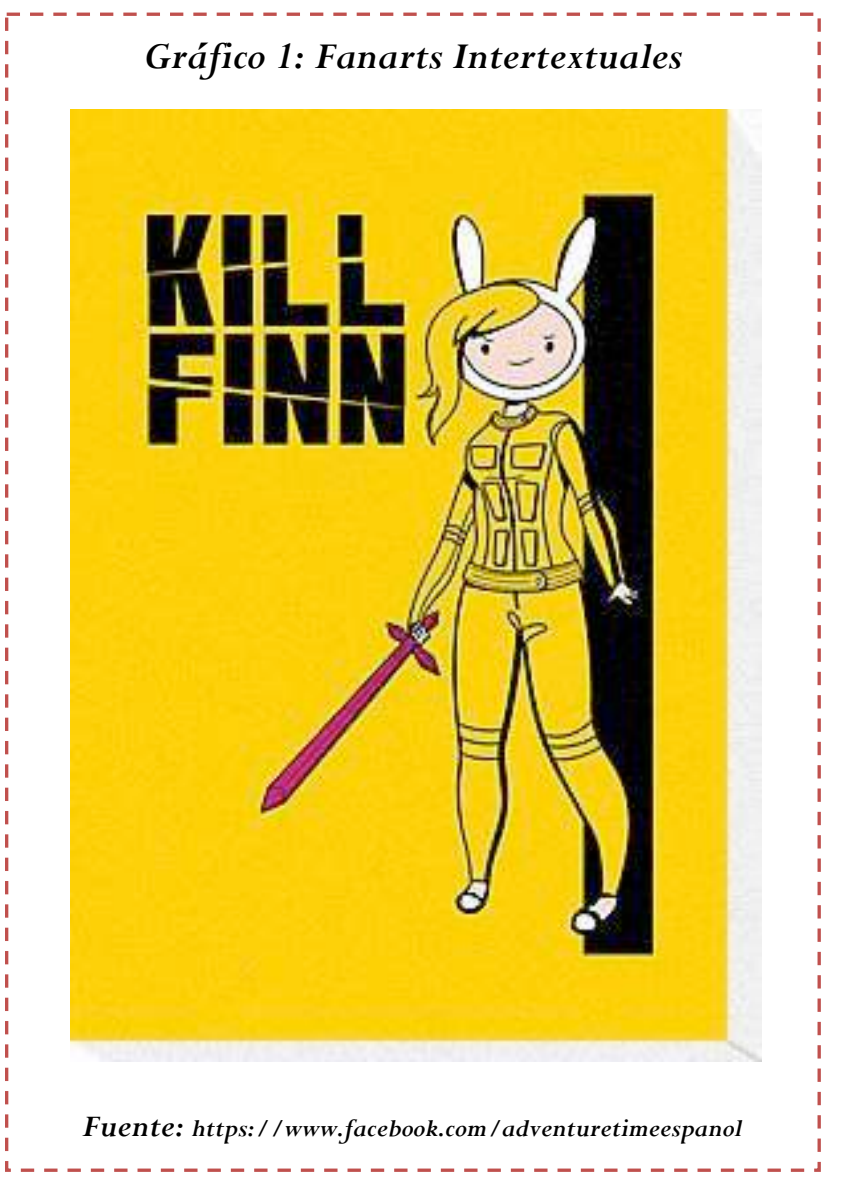

\subsection{Fanarts de reinvención}

El segundo grupo, que he optado por nombrar de Reinvención, está conformado por los fanarts que expanden la narración del relato canon de la televisión. A través de diferentes estrategias narrativas; expansión espacial, temporal, de personajes o de género. Este tipo de fanarts fue el más numeroso dentro de las publicaciones de la página de Facebook y por lo mismo fue necesario hacer una subclasificación de acuerdo a la estrategia empleada y contenido. Su función es ampliar el mundo narrativo del dibujo animado a través de personajes, escenarios o proyecciones temporales al futuro (forward) o pasado (flashback). Sin embargo, también muchas veces se modifican las decisiones narrativas que se toman en el relato canon, como la unión amorosa de algunos personajes 
o el género sexual de personajes principales. En este caso la audiencia sí se rebela ante los contenidos expuestos por el canon, y se atreven a hacer sus propias propuestas.

Iniciamos la subclasificación de este tipo de fanarts, con aquellos que juegan con el cambio de género sexual, es decir, personajes que en la historia canon son hombres, son dibujados en su versión femenina, y viceversa. En el gráfico Gráfico $\mathrm{n}^{\circ} 3$ podemos ver un ejemplo de este tipo de estrategia de modificación, con dos de los personajes principales de la serie que en Hora de Aventura son mujeres: La Dulce Princesa y Marceline, la vampira. Pero antes, considero necesario observar una imagen de los personajes originales de la serie, que se pueden observar en el gráfico.

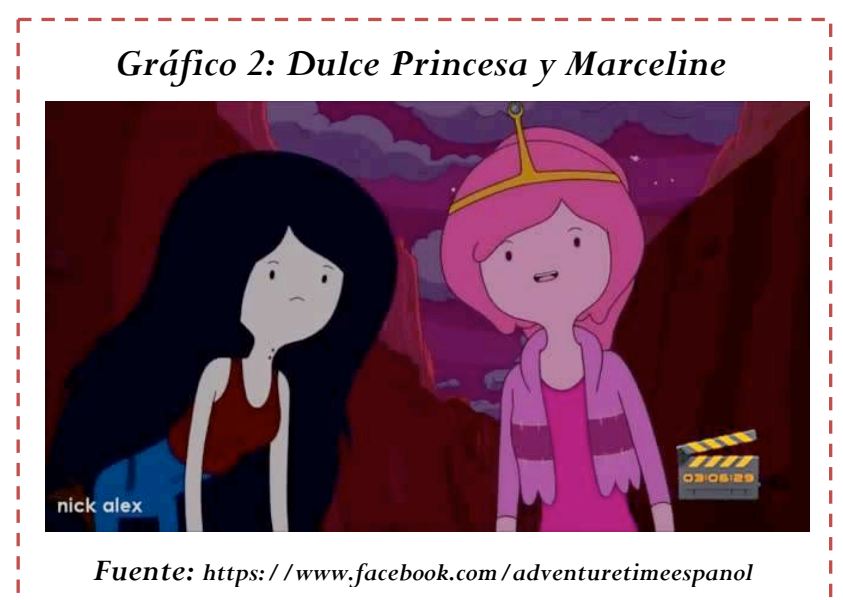

Además del cambio de género de los personajes, en el fanart del gráfico 3, podemos notar una expansión narrativa de tipo espacial, puesto que jamás ocurre esta escena en la serie original, ni siquiera existe un espacio parecido a este y los personajes Marceline y Dulce Princesa jamás cocinan pastelillos; la primera es músico y la otra científica.

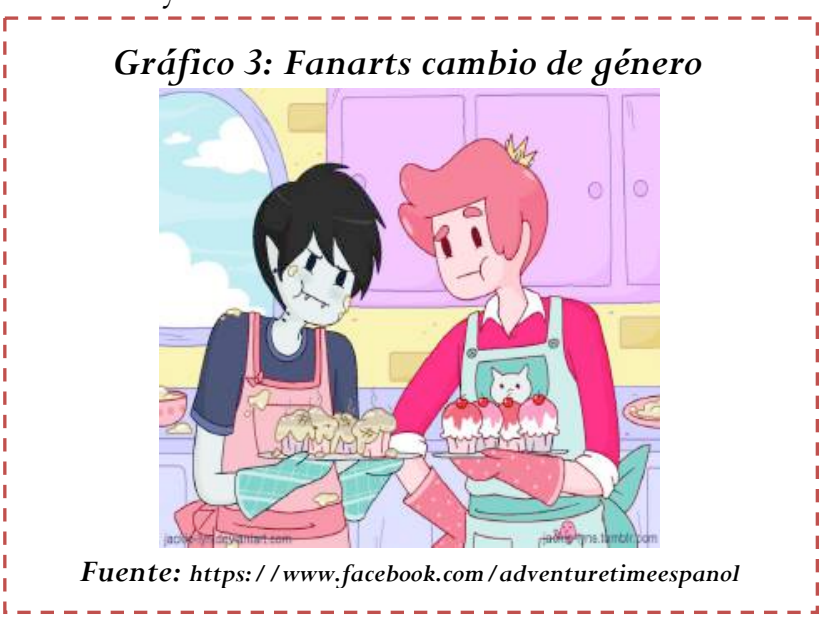

Es interesante resaltar que incluso con el cambio de género de femenino a masculino de los personajes dibujados en el fanart, parecen tener más estereotipos femeninos: dedicados a la cocina, repostería, en un espacio que se ha reservado durante mucho tiempo para la mujer: la cocina. Contrario a lo que sucede en el relato canon, donde ambas chicas se desenvuelven en espacios y actividades casi siempre ocupadas por los hombres: la música rock y la ciencia.

Otra de las subclasificaciones es la creación de nuevas parejas. Este tipo de fanarts es de los más populares y numerosos dentro de los de expansión narrativa. Hay una obsesión por ilustrar parejas que en el relato oficial no existen. Por ejemplo, una de las parejas favoritas del fanfiction es la de Finn (personaje principal) y la Dulce Princesa (Gráfico 4), que aunque en la misma serie sí aparece que está enamorado él de ella, nunca confiesa su amor porque la princesa de 18 años es mayor que él, quien tiene 12. Sin embargo, es algo que a los fans no les importa porque tienen la capacidad de modificar ese detalle a través de sus creaciones. Podemos notar sin embargo que en este fanart (Gráfico 4) no hay una intención por emular el estilo de la serie original, sino que se imita un estilo de anime japonés: ojos grandes, rostros angulosos, cabellos brillantes. Esta pareja es muy popular también en la conversión de género de ambos, Fiona y DP, que son Finn en su versión femenina y Dulce Princesa en su versión masculina.

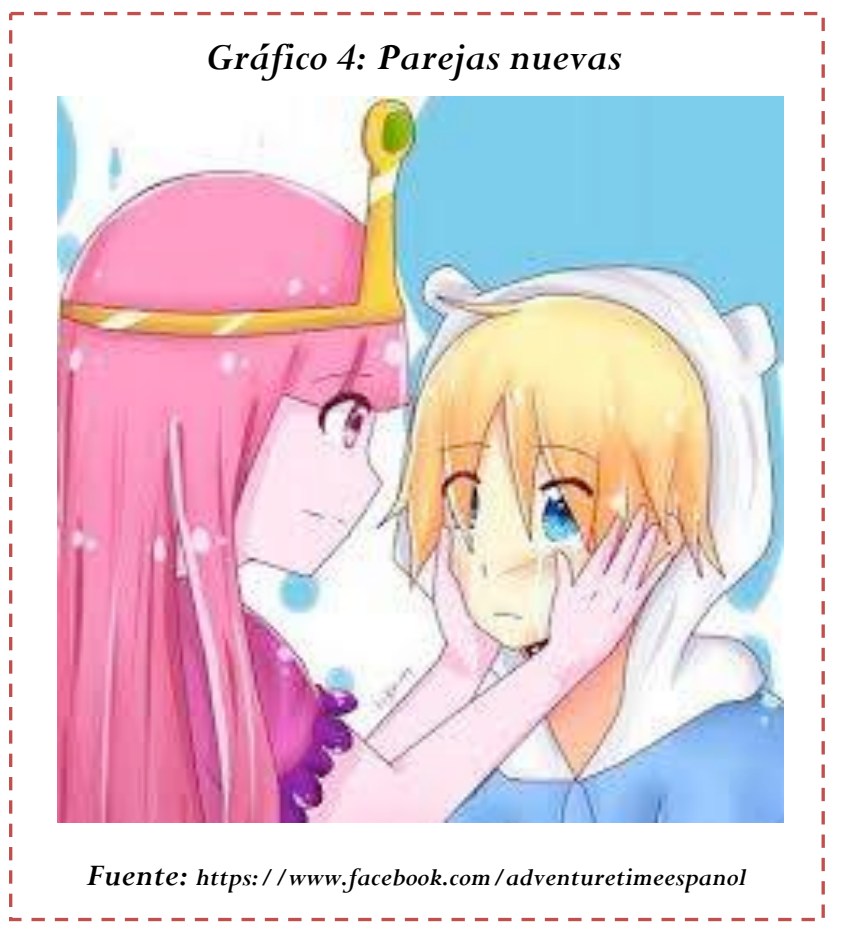


Aunque existen parejas heterosexuales, en su mayoría las parejas que se recrean en los fanarts son homosexuales. En el gráfico 5 podemos observar cómo Marceline y la Dulce Princesa, que en relato canon son incluso hasta enemigas, aparecen besándose. También sucede con los mismos personajes pero en su versión masculina.

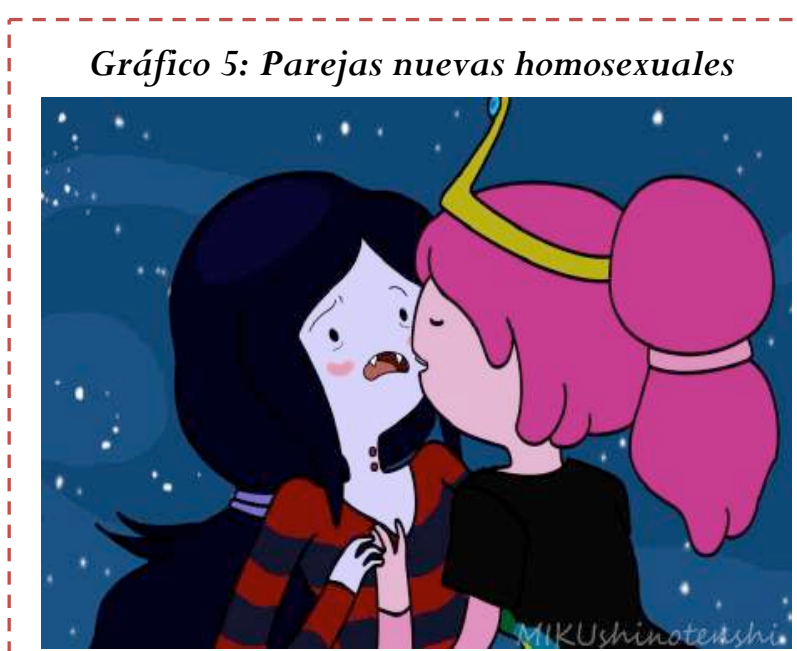

Fuente: https: / /www:facebook.com/adventuretimeespanol

Luego están las ilustraciones con carácter erótico, que forman parte de la otra subclasificación de los fanarts de expansión narrativa. Aquí generalmente se representa a los personajes femeninos, que son dibujados con cuerpos voluptuosos y poca ropa, o se crean escenas eróticas entre personajes de la serie. En el ejemplo del gráfico 7, vemos a una de las protagonistas de la serie animada, la Princesa Flama con un vestuario provocativo y un cuerpo voluptuoso, transformando la imagen del relato canon, ya que es una adolescente que viste con un atuendo de princesa: vestido largo naranja con amarillo y un cuerpo sin curvas pronunciadas como podemos observar en el gráfico previo, número 6 .

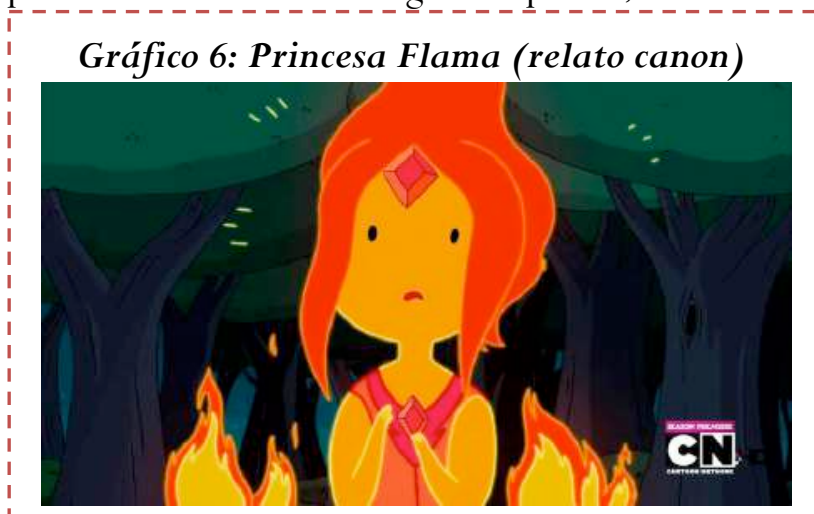

Fuente: https: //www.facebook.com/adventuretimeespanol
Los fanarts eróticos son una clara expansión respecto al relato canon, ya que son situaciones que nunca son transmitidas en televisión, mucho menos porque trata de un dibujo animado emitido para niños.

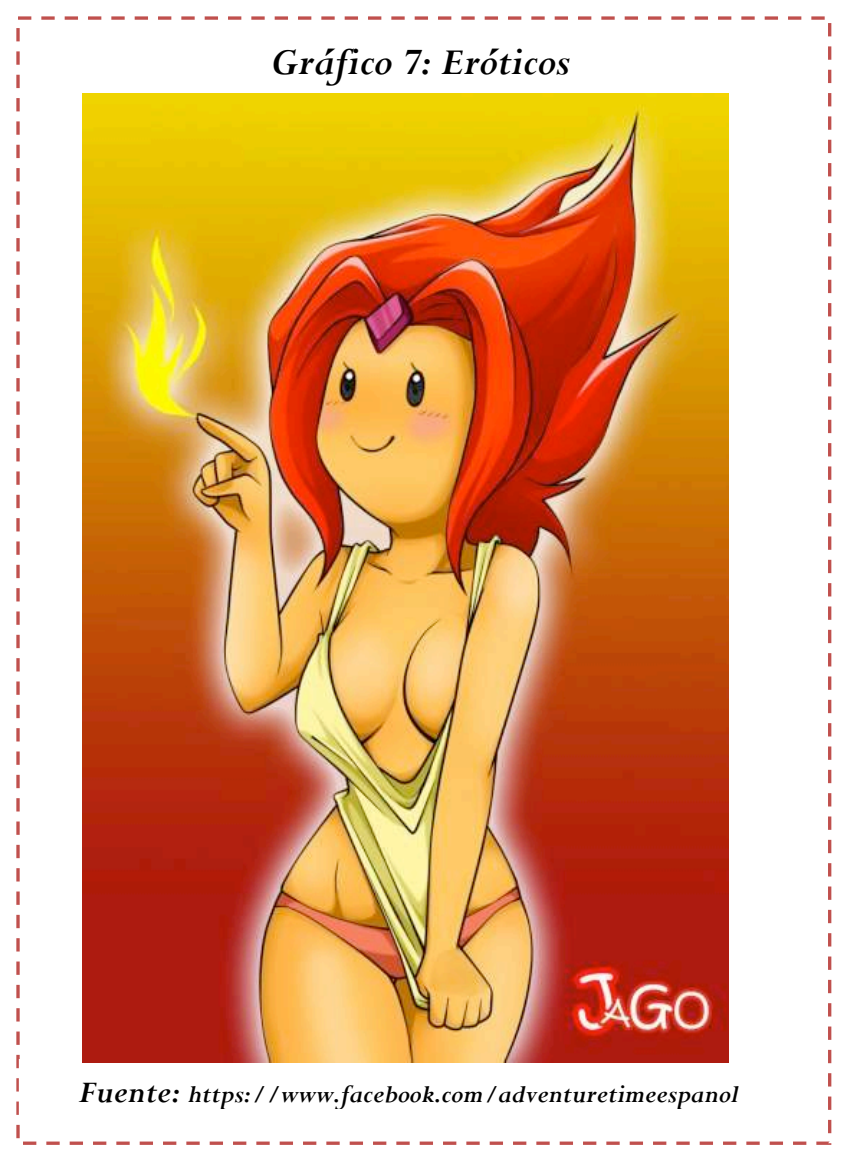

En este caso, la estética original si se conserva aunque el cuerpo es mucho más estilizado y realista, es decir que las formas no son tan simplificadas como sucede con el dibujo animado televisivo.

Finalmente están aquellas ilustraciones que se encuentran en la subclasificación de expansión temporal, y son aquellas que se atreven a hacer propuestas del futuro (forward) o pasado (flashbacks) del relato de la serie. Muchas veces se dibujan a personajes pequeños de la serie, ya como adultos; o bien personajes que son adultos en la serie, como niños, y se proyecta su situación de vida. Por ejemplo, en el gráfico 8 podemos ver en que el personaje principal de la serie, Finn, se dibuja como un adulto que tiene una pequeña hija con la Princesa Flama, personaje que en la serie es tan sólo su novia. Se dibuja incluso un escenario de fondo, con un sillón verde, un tapete y un florero, que parece ser la sala de estar de su hogar. Así pues se fantasea con el 
futuro de los personajes de Hora de Aventura, creando situaciones que no son transmitidas desde televisión.

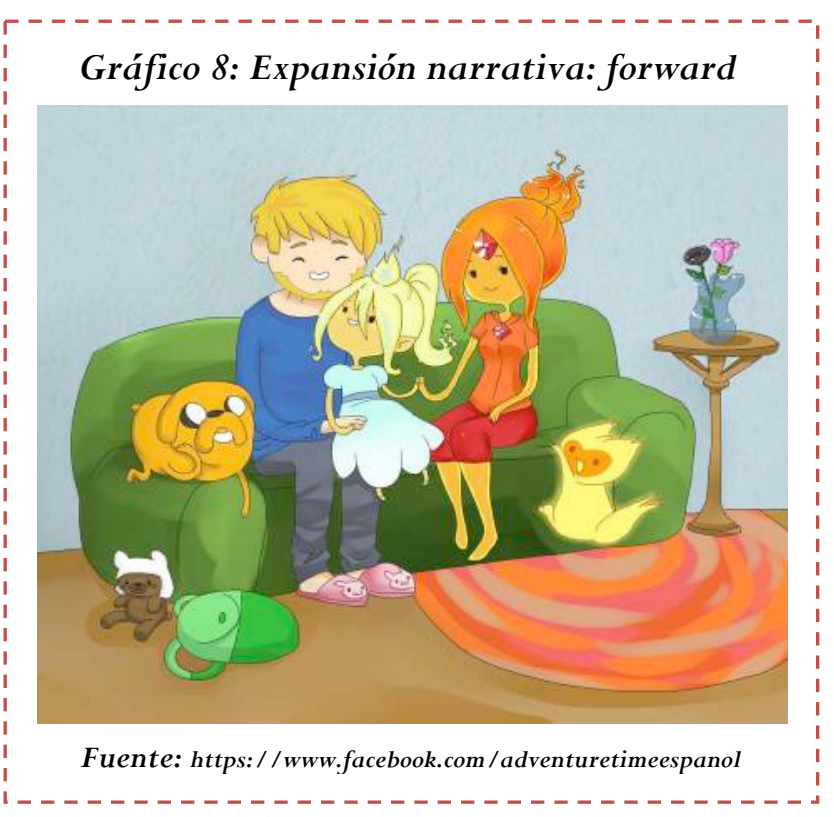

otro tipo de expansión temporal es el flashback, uno de los personajes más dibujados en el pasado es El Rey Helado, quien en el relato oficial figura como el adversario principal, debido a su obsesión por robar princesas del Reino de Ooo. Es un personaje bastante loco y de comportamiento absurdo, aunque es el adversario no es muy peligroso pues su máxima agresión es querer casarse con princesas. Hay capítulos donde muestran el pasado de este personaje antes de la Guerra nuclear que termina con el planeta tierra y da lugar al mundo post-apocalíptico donde se desarrolla la historia: el Reino de Ooo. A partir de estos capítulos se recrean escenas del pasado de ese personaje, como podemos observar en el gráfico 9 .

\section{Gráfico 9: Expansión narrativa: flashback}

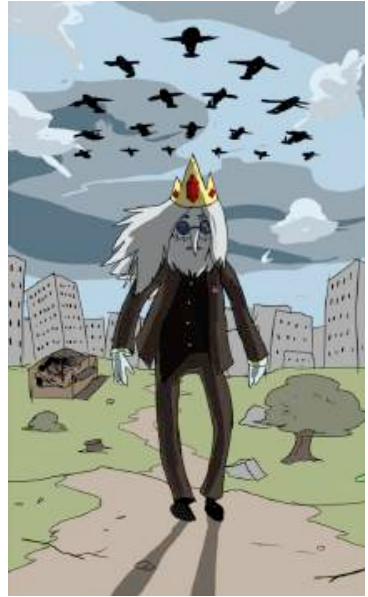

Fuente: https: //www.facebook.com/adventuretimeespanol
Así pues, el mismo relato canon funciona como un detonador para los fanfictions de expansión narrativa. En este caso el tipo de relación entre las creaciones de los usuarios y la de los productores es muy estrecha.

\subsection{Fanarts reflexivos-motivacionales}

Los fanarts que entran en la categoría de reflexivos, tienden a capturar escenas de capítulos y utilizar una de las frases dichas en la serie, con estas imágenes se resaltan las cualidades y valores que transmite el dibujo animado. El fanart del gráfico 10, captura la escena del capítulo 19 de la primera temporada, llamado "Duque". Aunque este fanart no implica la creación de la imagen, porque se toma de una escena que aparece en el relato canon, hay una intención creadora al captura un momento del episodio y presentarlo en un formato visual, resaltando el mensaje reflexivo.

Así como este ejemplo, se encuentran muchos fanarts enfocados a retratar las "enseñanzas" que desde el relato canon se hacen, o bien, los sentimientos de los personajes con los que se identifican, que muchas veces son amorosos, y en este sentido no se puede hablar tanto de una expansión narrativa pero sí de los nexos de complicidad y empatía que la audiencia hace con la serie de ficción que acostumbra ver.

\section{Gráfico 10: Fanarts reflexivos-motivacionales}

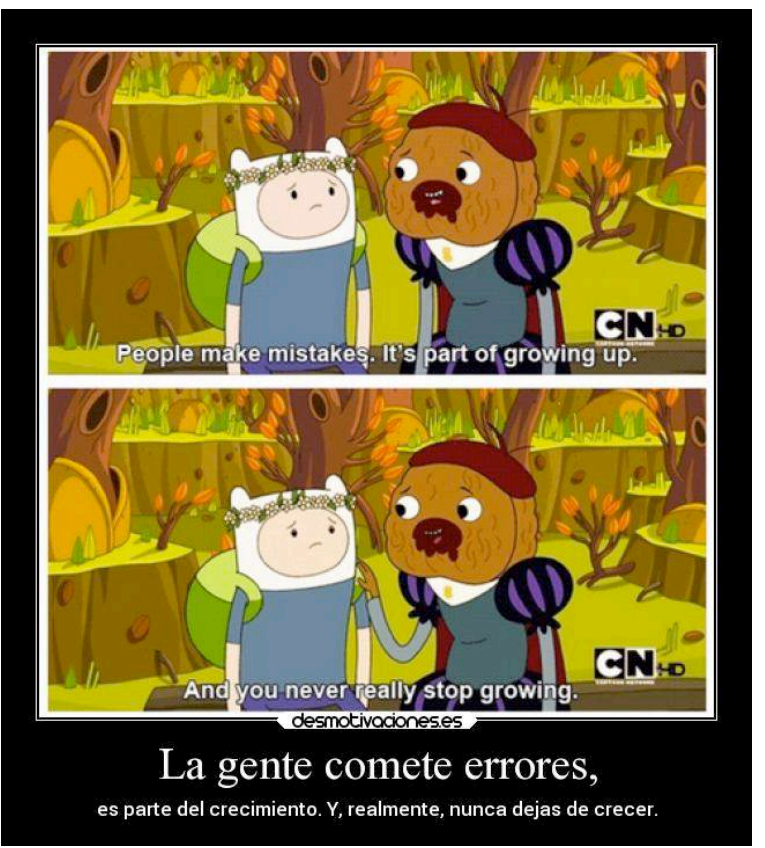

Fuente: https: / /www.facebook.com/adventuretimeespanol 
El nexo de este tipo de fanarts con el relato canon es muy estrecho, ya que básicamente hace un ensamblado con escenas de la serie animada.

\subsection{Fanarts humorísticos}

Finalmente se encuentran los fanarts humorísticos, clasificación que surge de acuerdo al tipo de contenido que es gracioso. Estas imágenes se crean con una intención de provocar risa, también guardan una relación estrecha con el relato oficial, ya que generalmente son capturas de pantalla de escenas de capítulos, con caras graciosas y frases dichas por personajes, pero que construyen una especie pastiche al tomar personajes de otros mundos narrativos alejados de manera intencionada, como veremos en el gráfico 11 .

En este fanart se toma una escena del capítulo "Rastro de calor" de la segunda temporada, donde aparece la Princesa Grumosa acampando en el bosque y gritando porque su lata de frijoles se cae al piso, ya que es lo único que tiene para comer, al final de las viñetas se agrega un cuadro con la imagen de Spiderman que tiene un gesto de pesar que hace parecer que comparte la misma escena y preocupación por los frijoles que Grumosa. Esta imagen resultará graciosa sólo para quien conoce a los personajes y quizás hasta la situación del capítulo del cual se toma la escena.

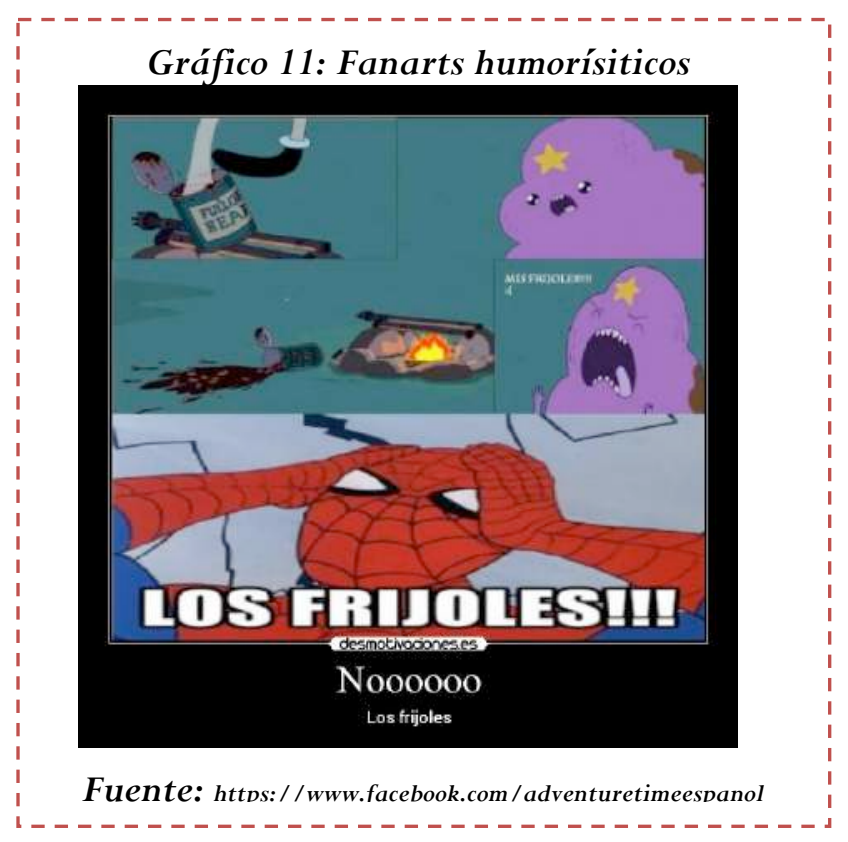

De esta forma se provoca una especie de exclusividad en el entendimiento de los fanfictions, que se restringe a usuarios que comparten el mismo fanatismo por la serie Hora de Aventura. Porque como bien señala Carlos Scolari (2013) los fans de las narrativas transmedia "son evangelizadores de tiempo completo que no pierden la ocasión para promover su narrativa" (Scolari, 2013:41).

\section{Conclusiones}

La revisión de los fanarts expuestos en la página de Facebok dedicada al dibujo animado Hora de Aventura, nos deja ver que el proceso de recepción se modifica con Internet, puesto que permite formar parte de una comunidad compuesta por miles de personas interesadas en el mismo tema sin ninguna restricción física o geográfica, donde es posible no sólo ver los capítulos de la serie de ficción, sino compartirlos, comentarlos, hacer hipótesis sobre los misterios planteados por el relato oficial y modificar y ampliar el mundo propuesto.

En este estudio de caso, se comprueba que la expansión narrativa se estimula por medio de "relatos abiertos" (Rodríguez y Molpereces, 2014), que proponen un mundo narrativo amplio con muchos espacios en blanco para que el espectador pueda llenarlos. De esta manera, en Hora de Aventura se plantea un relato base situado en un mundo post apocalíptico que ya pone en duda los antecedentes y el tema de la guerra nuclear, que los mismos usuarios van a completar con sus creaciones, como veíamos en el fanart de proyección del pasado (flashback) de uno de los personajes de la Serie (Gráfico 9). Esto se conecta con la profundidad (drillability) una de las características que Henri Jenkins (2009) menciona como constitutiva de las narrativas transmedia, que refiere a la voluntad de los fanáticos por profundizar en la historia del relato canon, buscando información, creando hipótesis para explicarse las situaciones planteadas, creando piezas de fanfiction, etc. El receptor toma entonces una posición activa para la construcción del relato que mira. 
Por otro lado, los fanarts no sólo se crean para complementar los recovecos que deja la historia oficial sino que también son una forma de rebelarse ante las decisiones de los mismos productores, o incluso modificar las propuestas hechas por ellos, en este caso se encuentran los fanfictions que modifican el género sexual de los personajes o las características físicas, e incluso su situación sentimental con otros personajes. Los receptores de las narrativas transmedia no esperan a que el relato canon cumpla sus expectativas, ellos tienen la capacidad de crearlo y modificarlo en cualquier momento en espacios alternos. Sería muy interesante analizar los significados que tienen estas modificaciones, que van siempre en un sentido de contracorriente hacia contenidos que no son todavía aptos dentro de las narrativas oficiales. Por ejemplo, en el caso de Hora de Aventura, que se sitúa como un dibujo animado para niños, los fanarts que se crean son siempre de carácter erótico o relaciones explícitas entre parejas del mismo sexo, tocando temas que jamás podrían ser transmitidos en televisión.

Finalmente podemos hablar de fanarts relacionados con los principios de inmersión (immersion) y extraibilidad (extractability) mencionados por Jenkins (2009), que establecen lazos entre la ficción de la NT y la realidad cotidiana de los receptores. Así pues, la experiencia de consumir un producto transmedia no queda simplemente en el entretenimiento, sino que se extiende hacia un sentimiento de empatía con las situaciones planteadas desde la ficción, tal como sucede con los fanarts reflexivos-motivacionales, que aluden a frases y sentimientos de personajes con los que el usuario puede sentirse identificado.

Los fanarts también cumplen una función de selectividad, ya que la mayoría sólo pueden ser entendidos por las personas que comparten los mismos intereses y afición, casi a manera de código secreto. Esto es muy visible con los fanarts intertextuales, que tejen su relación con textos que forman parte de una cultura popular precisa.

Finalmente cabe destacar que la autoría se pierde en este proceso de producción desde la audiencia, ya que en internet es difícil todavía controlar esto gracias a la capacidad de difusión con la que cuenta. Así es casi imposible rastrear desde dónde se crean los fanarts que se comparten en las redes sociales o comunidades web de una serie de ficción. La posición de los receptores y usuarios de estas comunidades virtuales aún no es del todo creativa, puesto que sólo comparten contenidos hechos por prosumidores, sin embargo sí se vuelve más activa que la de viejas audiencias.

\section{Referencias}

- Orozco, Guillermo (2001). Televisión, audiencias y educación. Buenos Aires: Norma.

- Rincón, Omar. (2011). «Nuevas narrativas televisivas: Relajar, entretener, contar, ciudadanizar, experimentar. Comunicar no 36, XVIII, 43-50.

- Scolari, C. A. (2009). «Transmedia storytelling: Implicit consumers, narrative worlds, and branding in contemporary media production». International Journal of Communication 3, 586-606.

- Scolari,C.A. et al. (2012) «Narrativas transmediáticas, convergencia audiovisual y nuevas estrategias de comunicación». Quaderns del CAC 38, vol. XV (1) - junio 2012 (79-89). Barcelona.

- Scolari, Carlos (2013). Narrativas transmedia. Cuando todos los medios cuentan. Barcelona: Deusto.

- Virino, C. (2006). «No es televisión, es HBO: La búsqueda de la diferencia como indicador de calidad en los dramas del canal HBO». (Spanish). Zer: Revista De Estudios De Comunicacion, 11(21), 23-33.

- Adventure Time en español (2013, Abril 15Mayo 16). Consultado el 16 de mayo de 2013 
por última vez. En:

http//www.facebook.com/adventuretimeesp anol

- Jenkins, H. (2003, January 15). Transmedia storytelling. Moving characters from books to films to video games can make them stronger and more compelling. Technology Review. Retrieved December 10, 2008, from http://www.t echnologyreview.com/biotech/13052/

- Jenkins, Henry. (2008). Convergence Culture. La cultura de la convergencia de los medios de comunicación. Barcelona: Paidós.

- Jenkins, Henry (2009). «The Revenge of the Origami Unicorn: Seven Principles of Transmedia Storytelling». En H. Jenkins, Confessions of an Aca-Fan (blog). Entrada del 12 de diciembre. Consultado el 11 de mayo de 2013,

http://henryjenkins.org/2009/12/the_reven ge_of_the_origami_uni.html (parte 1) y

http://henryjenkins.org/2009/12/revenge_ of_the_origami_unicorn.html (parte 2)

- Rodriguez, Isabel y Molpereces, Sara (2014). «The inside experience y la construcción de la narrativa transmedia. Un análisis comunicativo y teórico-literario». Cua- dernos de Información y Comunicación, vol. 19 -Junio 2014 (315-330)

- Rojek, C. y Urry. (2000). Touring Cultures. Transformations of Travel and Theory. London and NY: Routledge.

- San Salvador del Valle Doistua, R. (2009): "El tiempo acelerado". El País. Disponible en:

http://elpais.com/diario/2009/11/01/pais vasco/1257107999 850215.html (Última consulta: 02/03/2013).

- Sibilia, P. (2008). La Intimidad como Espectáculo. Buenos Aires: Fondo de Cultura Económica.

- Turkle, S. (2012): ¿Conectados pero solos?. TED. Disponible en: http://www.ted.com/talks/sherry turkle alone together.html (Fecha de consulta: 26/02/2013).

- Van Dijk, J. (1999): The network society. Social aspects of new media. London: Sage.

- World Leisure Recreation Association (1994): Carta para la Educación del Ocio. En S. Gorbeña; V.J. González. y Y. Lázaro. (1997). El Derecho al ocio de las personas con discapacidad (pp. 243-252). Documentos de Estudios de Ocio, 4. Bilbao: Universidad de Deusto.

\section{Forma de Citación}

CHÁVEZ ORDÓÑEZ, Verónica Itzel: ¿Qué pasa cuando los receptores crean? Expansión narrativa de una serie animada por medio de las creaciones de los fans. Revista Communication Papers, N 4, páginas 77 a 86. Departamento de Filología y Comunicación de la Universidad de Girona. Recuperado el de de 2 de: http://www.communicationpapers.es 